This item was submitted to Loughborough's Institutional Repository (https://dspace.lboro.ac.uk/) by the author and is made available under the following Creative Commons Licence conditions.

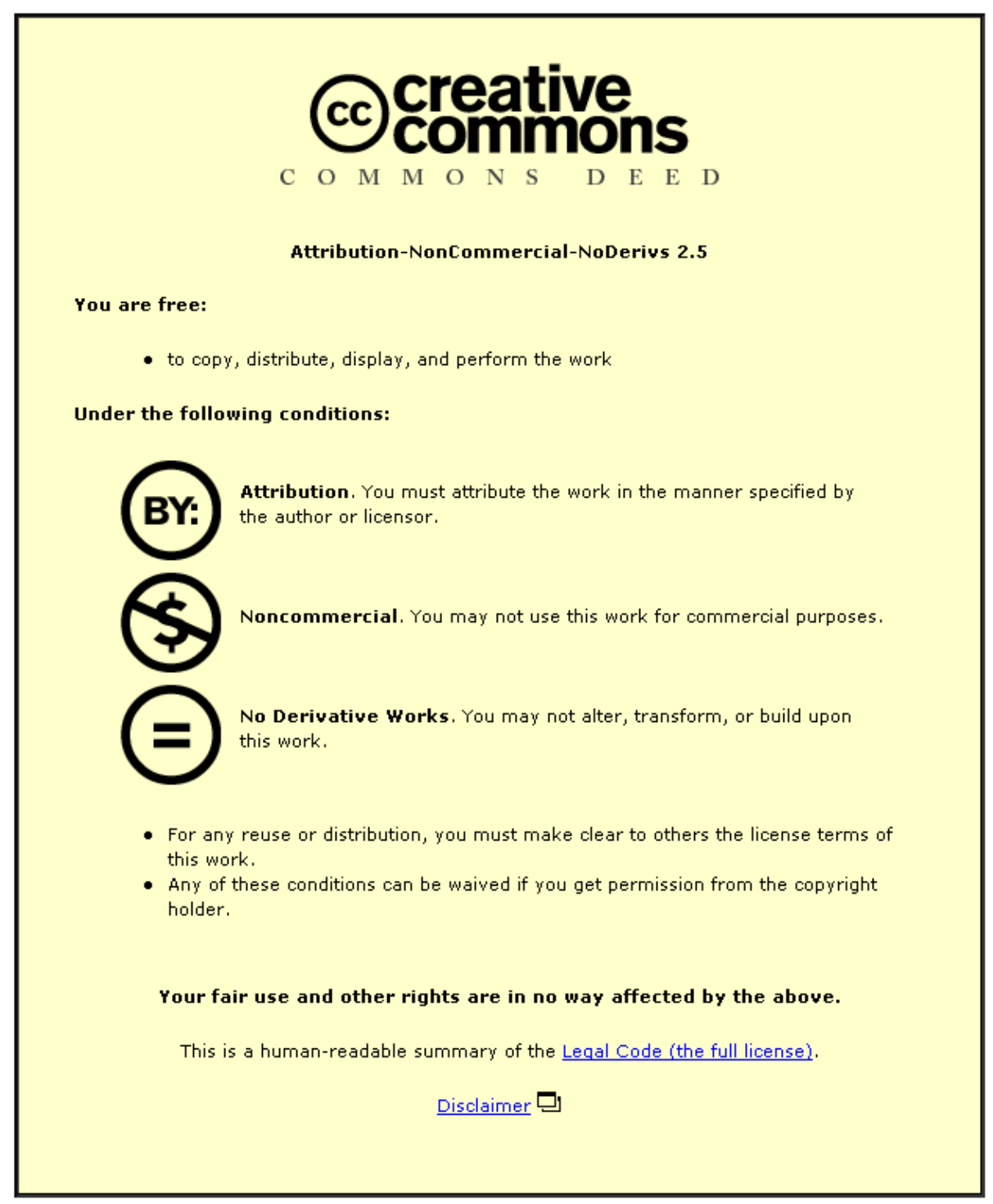

For the full text of this licence, please go to: http://creativecommons.org/licenses/by-nc-nd/2.5/ 


\section{Materials and energy assessment in Ceequal transport projects}

1 Shamir Ghumra BEng, AIEMA Research engineer, Aggregate Industries, Coalville, UK

2 Jacqui Glass BA, Dip Arch, PhD, FHEA Senior Lecturer in Architecture and Sustainable Construction, Department of Civil and Building Engineering, Loughborough University, Loughborough, UK
3 Matthew W. Frost BEng, PhD, MPWl

Lecturer in Geotechnical Engineering, Department of Civil and Building Engineering, Loughborough University, Loughborough, UK

4 Miles Watkins BSC, PhD, CEnv, FIEMA, FIQ Director Sustainable Construction, Aggregate Industries, Coalville, UK

5 Jo Mundy BA, MSC, DIC, PhD

Technical Leader, BREEAM Materials, BRE Global, Watford, UK
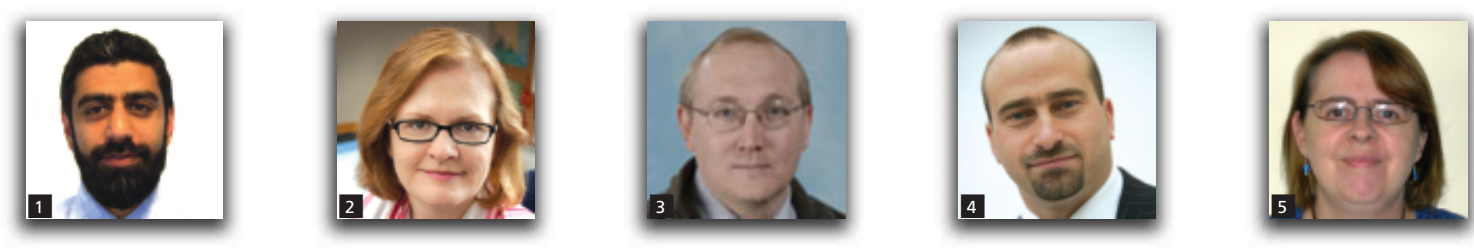

The growing prominence of sustainability assessment and carbon calculators in the transport sector has led to a greater general awareness of the sustainability issues associated with infrastructure projects. Ceequal, the assessment and awards scheme for improving sustainability in civil engineering and public realm projects, is identified as the leading methodology for assessing such projects in the UK. Ceequal evaluates sustainability by asking questions over 12 sections, including material and energy use, which previous research has identified as important topics for transport projects. This paper presents analysis of 24 Ceequal projects which are transportrelated. It shows that high scores in the material use category have a high correlation to overall project scores. Conversely scores in the energy usage section appear to show little relation to overall project performance. An evaluation of road projects within those assessed reveal a number of what can be considered core transport topics and other topics that have little impact on the overall Ceequal score. Therefore recommendations are made for the development of Ceequal, including the rationalisation of material and energy question sets. The methodology outlined in this work could also be extended to the remaining ten Ceequal sections to develop a suite of more specific assessment schemes focused on different categories of civil engineering projects.

\section{Introduction}

UK transport infrastructure is a diverse and complicated asset. Large transport projects frequently make headline news and are often characterised as negative from an environmental perspective. The growth of the UK economy has been underpinned by a strong transport infrastructure, but the management and expansion of this asset must be done in a demonstrably sustainable manner.

Ceequal is 'the assessment and awards scheme for improving sustainability in civil engineering and public realm projects'. It aims to improve the sustainability of projects from initial specification, through the design stage and on to final construction (see http://www.ceequal.com) by assessing sustainability across 12 core topics. Ceequal is supported by the Institution of Civil Engineers, the Construction Industry Research and
Information Association (Ciria), the Civil Engineering Contractors Association (CECA), the Association for Consultancy and Engineering (ACE) and a wide range of other industry organisations. It is considered to be the mainstream assessment methodology for civil engineering works and has been used on a number of major projects including those connected with the London 2012 Olympic Games (see http://www.ceequal.com/awards_ 046.htm).

In the wider construction industry the growing focus on sustainability and more specifically environmental issues has been further galvanised through the development of an increasing number of carbon calculators and assessment schemes (Ghumra et al., 2009). More focus has been given to the built environment by way of well-developed schemes such as the Building Research Establishment Environmental Assessment Method (Breeam) and 
the Code for Sustainable Homes, but developments in such assessments for civil infrastructure projects have been slower to emerge (Ghumra, 2009). Consequently the present research has been undertaken to understand specifically material and energy performance of projects that use Ceequal and to make recommendations for the long-term improvement of the assessment methodology to match the more robust analysis used in other construction sectors.

Although it is acknowledged that 'materials' and 'energy' are only two of 12 sections assessed in Ceequal, these represent two of the most significant challenges in addressing climate change and are themselves inexorably linked. By focusing on 'materials' and 'energy' assessment in a sample of Ceequal projects, it is envisaged that the research outputs can feed directly into forthcoming Ceequal revisions and updates for infrastructure.

The objectives of the present study were to understand the relationships between overall Ceequal project scores and section scores for materials and energy for a sample of Ceequal projects that are transport-related: namely road, rail or bridge focused. This will allow comparisons to be made between the different transport project types as these areas are significant for such projects.

The paper also discusses drivers for the focus on materials and energy in terms of policy from the government and initiatives from the private sector. The results identify key trends within the Ceequal materials and energy categories for the selected projects. The subsequent discussion and analysis probe further into selected road projects within the group analysed and reveal a number of topics that can be identified as core areas for such schemes and have little impact on the overall Ceequal score. Recommendations are therefore made for the development of Ceequal, including the rationalisation of materials and energy question sets and the application of the methodology developed to other civil engineering project types.

\section{Background}

Sustainability assessment in the UK has developed over the past few years. This section identifies the key policy drivers relating to construction and gives an overview of Breeam and Ceequal. Two key sub-sections in assessment methodology - life-cycle assessment (LCA) and responsible sourcing - are identified as mechanisms by which materials and energy use in particular can be assessed and managed.

\subsection{Policy drivers}

The Strategy for Sustainable Construction (HM Government, 2008) outlines six 'ends' to provide for sustainable construction: materials is identified as a key 'end' (in relation to the use of an increasing percentage of materials from responsible sourcing schemes) and climate change mitigation/adaptation is also included (with a strong focus on carbon reduction and flood risk management).
More recently, a consortium led by Forum for the Future (including the Highways Agency, the Rail Safety and Standards Board, Atkins and Balfour Beatty) produced the Carbon Management Framework for Major Infrastructure Projects; e21C Project Report (December 2009) (FFTF, 2009), in which Ceequal is identified as one of the methods that can be used for the environmental assessment of infrastructure projects. 'Materials' is identified in that report as one of the five key carbon 'spiders' which takes into consideration the embodied carbon $\left(\mathrm{CO}_{2} \mathrm{e}\right)$, waste, reuse and recycling and transport of materials to and from site. There is a clear link between some of the carbon that is expended in a construction project and the types of materials used. ISO standards specifically written for calculating whole-life carbon are also available (ISO 14067-1 (ISO, 2010)) as are UK methodologies such as PAS 2050 (BSI, 2008) and the BRE Environmental Profiles methodology (BRE, 2008).

The 'Low Carbon Construction Innovation and Growth Team's' emerging findings report of spring 2010 (HM Government, 2010) stresses the importance of acknowledging the whole-life impacts of materials; the report, however, does not emphasise the role of sustainability assessment schemes such as Ceequal in the effort to achieve lower carbon construction, which is a clear omission from the report. This focus on carbon reduction has spawned a generation of carbon calculators, some notable examples are listed here.

(a) A collaborative project between the Transport Research Laboratory (TRL), Mineral Products Association (MPA), Refined Bitumen Association (RBA) and Highways Agency; this has resulted in a carbon calculator for asphalt materials used in road pavements called Aspect (asphalt pavement embodied carbon tool; see http://www.sustainabilityof highways.org.uk) which considers the carbon impacts from product manufacture to installation.

(b) The International Road Federation Charger calculator (IRF, 2009).

(c) Project-specific calculators available from the Highways Agency (HA, 2009) and Environment Agency (EA, 2009).

\subsection{Breeam}

Part of the sustainability business of Building Research Establishment (BRE) is the range of building assessments known as the BRE Environmental Assessment Method (Breeam), which first started in 1990 and has grown to become one of the most wellknown and widely used building sustainability assessment tools in the UK. There are a growing number of Breeam schemes that cover the different requirements of particular building types such as offices, industrial, retail, prisons, courts, education, healthcare, and for other more unusual building types a Breeam bespoke scheme can be provided. The range of schemes available means that assessments are more tailored to a particular building type rather than having a completely generic approach.

Credits are the currency of Breeam and are awarded in ten 
Transport

Volume 164 Issue TR3
Materials and energy assessment in

Ceequal transport projects

Ghumra, Glass, Frost, Watkins and Mundy categories, these category scores are weighted to produce an overall score on a scale of pass $(30 \%)$, good $(45 \%)$, very good $(55 \%)$, excellent $(70 \%)$ and outstanding $(85 \%)$. There are ten sections in Breeam and materials and energy are stand-alone sections within these.

\subsection{Ceequal}

Whereas Breeam focuses on buildings, Ceequal is the assessment and awards scheme for improving sustainability in civil engineering and public realm projects. The most recent version of Ceequal is version 4 (November 2008; Ciria (2008)) and has gained widespread recognition in the UK over the past 10 years (Greeman, 2009). The Ceequal scheme was developed to enhance the environmental and social performance of civil engineering projects to give clients, designers and contractors an incentive to adopt and improve upon best practice. Ceequal is recognised as the key environmental sustainability scheme for civil engineering projects (Ghumra et al., 2009) and is often compared to Breeam for buildings (Leckie, 2010), which is slightly misleading as the two schemes are technically very different and approach their respective projects in different ways. Although Ceequal has been used or is in the process of being used to assess projects worth more than $£ 15$ billion (July 2010), the number of completed projects assessed using the latest version is limited at the time of writing; however, there are a large number of interim awards. Little academic research regarding Ceequal has been undertaken to date; this work is therefore of great value to the civil engineering community.

A range of awards is available (depending on the extent to which the wider project team is involved in the assessment).

(a) Whole project award.

(b) Client and design award.

(c) Design only award.

(d) Construction only award.

(e) Design and construct award.

Ceequal is a points-based system and asks questions over 12 sections; the weightings are embedded within the question scores so that the overall score falls into a standard percentage. The four grades of award are pass (30\%), good (40\%), very good $(60 \%)$ and excellent (75\%). The 12 sections and associated weightings within Ceequal are shown in Table 1.

One of the key principles of Ceequal is that it is not possible to achieve a $100 \%$ score for any single project because of some mutually exclusive questions (Venables, 2005). However, as Ceequal encompasses all civil engineering works (due to the flexible question set) it does then lack the focus of evaluation that road projects or indeed any other large sector of civil engineering works would perhaps benefit from; for instance in a road-specific scheme particular focus could be given to the use of active traffic management systems or variable speed cameras. Some basic project questions must be answered and each section contains

\begin{tabular}{lr} 
Ceequal section & Weighting \\
\hline Project environmental management & $12 \cdot 0$ \\
Land use & $8 \cdot 2$ \\
Landscape & $6 \cdot 9$ \\
Ecology and biodiversity & $8 \cdot 5$ \\
Archaeological and cultural heritage & $6 \cdot 2$ \\
Water issues & $8 \cdot 9$ \\
Energy & $8 \cdot 5$ \\
Use of materials & $9 \cdot 5$ \\
Waste & $8 \cdot 7$ \\
Transport & $7 \cdot 6$ \\
Nuisance to neighbours & $7 \cdot 3$ \\
Community relations & $7 \cdot 7$
\end{tabular}

Table 1. Ceequal (v3.1) (Ciria, 2007) weightings

questions that form part of the mandatory requirement, but many questions can be 'scoped out' as being not relevant to a particular project. As such, the combination of award and project types means that there are many potential combinations of assessment to suit a range of project needs (see http://www.ceequal.com). However, this is not a perfect approach as some questions are consequential in the construction process so a contractor seeking a construct-only award might be hindered in some cases where information relating to decisions made at the design stage is not available.

The Ceequal process involves the discussion between the project assessor and a verifier and once agreement has been reached the assessor can collate the project evidence and complete the project assessment. The verifier checks the work of the assessor and then a ratification process takes place before the final award is confirmed.

Of the two main sets of questions of interest in this research the materials section consists of eight main parts, each with subquestions: basic principles; minimising material use and waste; timber; using re-used and/or recycled materials; minimising use and impacts of hazardous materials; durability and maintenance; future de-construction or disassembly. The energy section consists of three broad parts: basic principles; energy in use; and energy performance on site. These headings are based on version 3.1 of Ceequal, but recent additions to the latest revision (version 4; Ciria (2008)) include responsible sourcing for materials and a greater emphasis on life-cycle carbon impacts of materials and components. Version 4 of the Ceequal manual also acknowledges that the energy section is linked to the materials section through the use of life-cycle assessment, as described in the next section.

\subsection{Life-cycle assessment}

Life-cycle assessment (LCA) was initially developed in the late 1960s and early 1970s. It has since become a valued and recognised tool for the assessment of a range (including climate 
change, mineral depletion, eutrophication etc.) of environmental impacts for products and materials (Ghumra et al., 2011). LCA procedures are harmonised in the ISO14040 series, which itself sits within the widely applied ISO14000 series of environmental management standards (Ghumra, 2009). For the majority of construction materials, the life stage begins at the extraction and processing of raw material, followed by production/construction, then the in-use/maintenance phase and finally on to demolition, disposal or reuse. LCA aims to give a whole-life understanding and insight into the processes within the life cycle of a product and can be used to identify areas of significance to direct resources in an effective manner.

\subsection{Responsible sourcing}

Schemes recognised for responsible sourcing have traditionally been focused on the timber sector such as the Forestry Stewardship council (FSC). As concrete and other construction materials had no opportunity to demonstrate similar credentials the BRE launched the BES 6001 Framework Standard for the Responsible Sourcing of Construction Products in late 2008 (BRE, 2009). The framework 'provides a holistic approach to managing a product from the point at which a material is mined or harvested in its raw state through manufacture and processing, through use, reuse and recycling, until its final disposal as waste with no further value' (see http://www.greenbooklive.com). The standard seeks to ensure a level playing field between competing construction materials under a single framework. The requirements and associated actions have been structured into three components.

(a) Organisational management requirements.

(b) Supply chain management requirements.

(c) Environmental and social requirements.

The framework standard contains key questions relating to both the LCA of the products and the carbon (and therefore directly linked to energy) of the materials. The standard is more qualitative by setting thresholds of rigour than actual impact levels for compliance. To date all the leading aggregate companies in the UK have had products certificated to BES 6001 (see http:// www.greenbooklive.com).

\subsection{Materials and energy}

Each of the two assessment schemes mentioned previously contain sections on materials and energy; different weightings are applied to these issues in the two schemes. Material use is weighted at $9.5 \%$ in Ceequal and $12.5 \%$ in Breeam and $8.5 \%$ and $19 \%$ for energy use, respectively. Energy by this measure is the most significant section for Breeam assessments whereas it is joint fourth in Ceequal. The materials section in both schemes is the second most weighted. The large difference in the weighting applied to each energy section is perhaps a reflection of the inuse impacts during the asset life cycle. A building during its operation will consume more energy than its construction. The same cannot be said for civil engineering works as the asset itself does not consume energy (excluding maintenance) but the inter- action of people with the asset creates impacts such as people driving on a road. Breeam and Ceequal have therefore evolved in the weightings to take fundamental issues like this into account in the assessment process.

These two sections are linked through measures such as embodied carbon and embodied energy. This research builds upon previous research (Ghumra, 2010) where it was found that the average scores of a sample of Ceequal projects were lowest for materials and energy use. As measures are put in place to reduce the in-use phase impacts of the life cycle of an infrastructure project, the embodied impacts of the materials will contribute an increasing share of the entire life cycle impacts.

\section{Methodology and data analysis}

The research study considered a sample of 48 Ceequal project awards; these were all based on version 3.1 of the Ceequal manual and all were based on completed project awards (interim projects were excluded as a number of questions are not applicable at the interim stage of a project). Exactly 24 of these projects were either road, rail or bridge related and hence grouped as 'transport' projects. Figure 1 shows the breakdown of the different types of projects in the sample set.

A quantitative study by simple regression analysis (square of Pearson's correlation coefficient) was used to calculate the correlation between overall project scores and particular section scores (i.e. materials and energy), as a whole (i.e. collectively for road, rail and bridges) and at individual project type level.

To present a logical flow to the results and subsequent discussion the overall relationships between the 'transport' project types was calculated first to give regression coefficients; scatter diagrams were used to show the spread of data for each project type for materials and energy questions. This allowed trends to be identified within project types and also if certain project types perform consistently well or poorly. A further set of tables show the number of scoring questions for materials and energy for

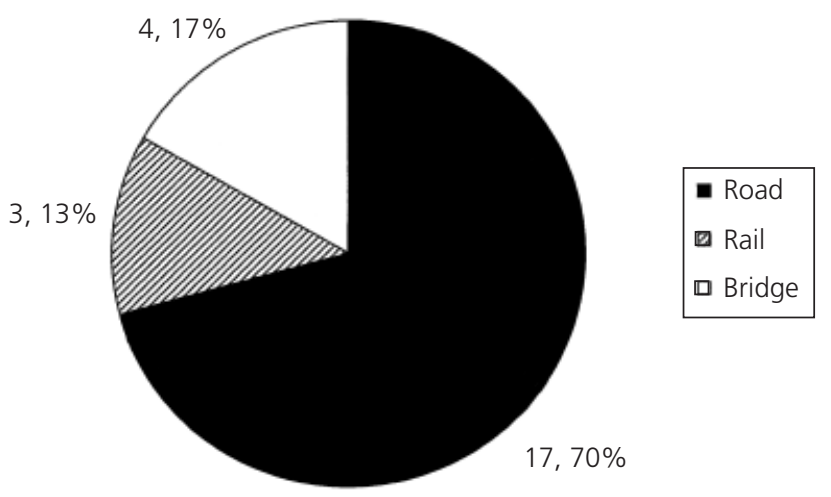

Figure 1. Breakdown of Ceequal project types (total $=24$; number of projects in each sector shown first) 
Transport

Volume 164 Issue TR3
Materials and energy assessment in

Ceequal transport projects

Ghumra, Glass, Frost, Watkins and Mundy roads, rail and bridge projects. Due to the dominance of road projects within the sample, it is possible to make more robust statements about core questions that are either integral to road projects or appear to have little influence.

As the data have been provided by Ceequal to undertake this research, a level of client confidentiality has to be maintained, as such it is not possible to further categorise any of the project types; therefore, for example, road projects could consist of new build, widening, maintenance or traffic management projects.

\section{Results}

This section describes the general trends in relation to Ceequal project score and how this relates to scores in the materials and energy sections (Figure 2) it also shows the scatter plots of these distributions (Figures 3 and 4).

The general regression analysis shown in Figure 2 shows that transport projects' material section scores have a relatively strong positive correlation with the overall project score. Conversely scores in the energy section appear to have little relationship to the overall project score. The bias of the results towards the road projects is quite apparent when looking at both materials and energy regression coefficients. Material scores are generally very good (average of $72 \%$ ) whereas scores for the energy section were $40 \%$ or lower; again, this is due to the higher number of road projects in the sample. Therefore the average score for transport projects is very close to that of road projects.

The scatter plots (Figures 3 and 4) highlight the dependency of the dataset on the road projects. There is a clear general positive correlation in Figure 3 for materials but the spread of data points in Figure 4 means it is not possible to make any generalisations about energy data. The line of equality on each of these two plots clearly shows the general trend of materials scores falling around the line, whereas this is not reflected in the energy graph with the majority of the data well below the line.

The uptake for the materials questions by project type is shown in Table 2 and similarly for energy in Table 3. The asterisk indicates questions that cannot be scoped out (i.e. are mandatory). The 'projects scoring' is based on the number of projects for each project type to which that question scored some points (i.e. it has not scored zero, has not been scoped out and is applicable to the project type).

Road projects seem to assess materials well across the entire question set: all of the optional questions have over 50\% uptake and the two worst-performing questions are 8.5.2 (use of biodegradable and low volatile organic compound (VOC) coatings and treatments) and 8.7.1 (design for disassembly). As the sample set is reasonable (17) it would be interesting to see if

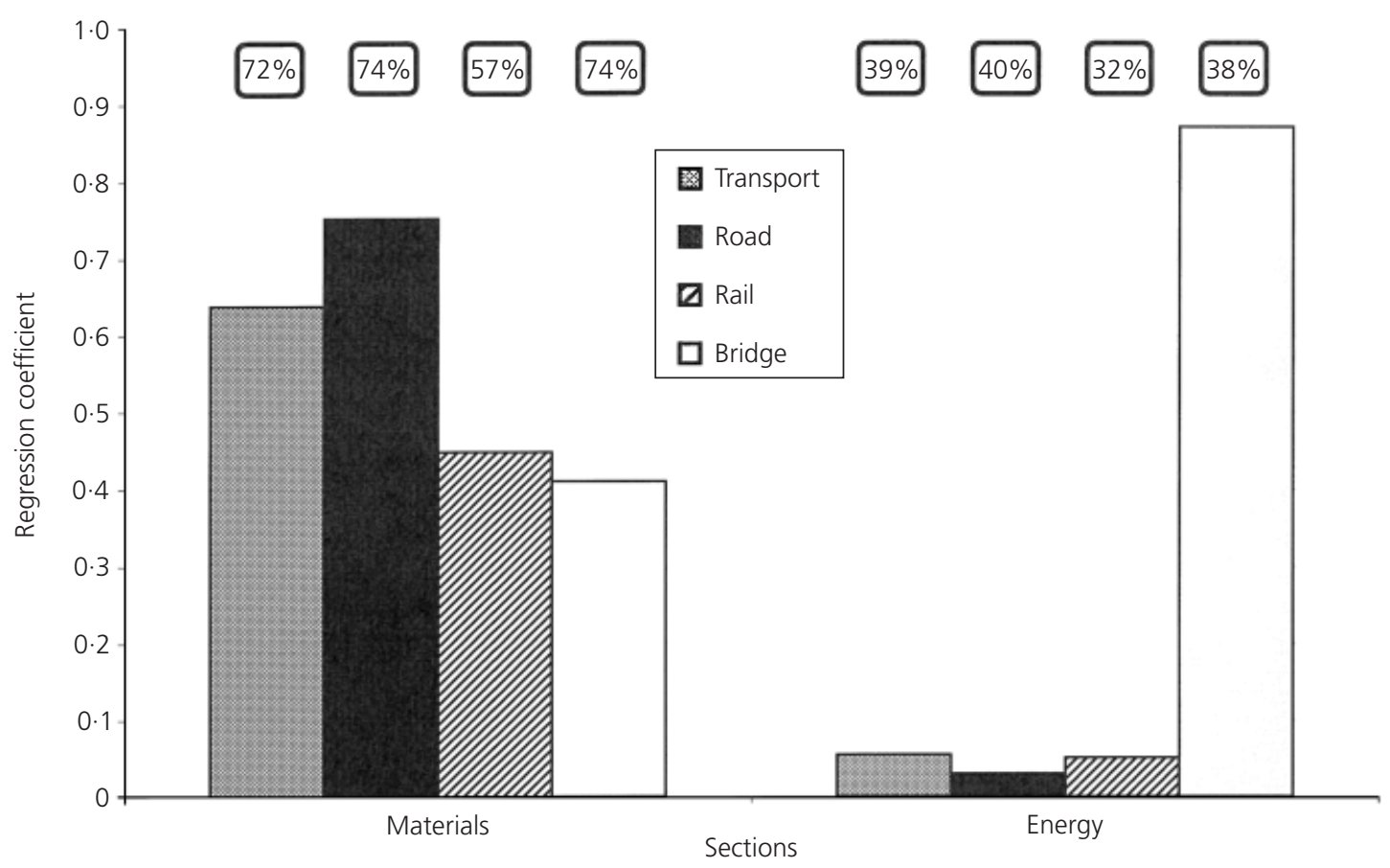

Figure 2. Regression data for materials and energy transport projects; the percentages in the boxes immediately above the corresponding bar on the graph are the average scores achieved for that project type in the project assessment 


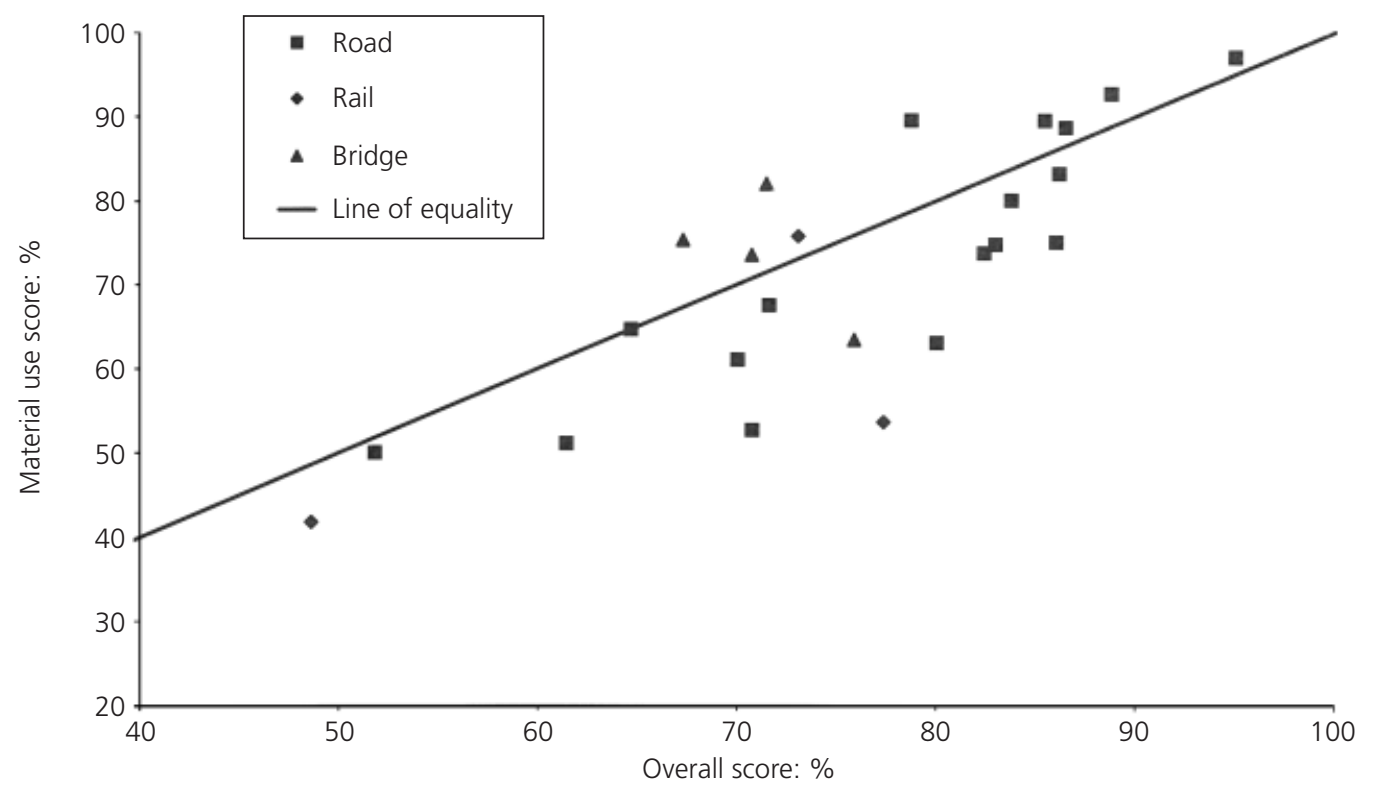

Figure 3. Scatter plot of materials scores for transport projects

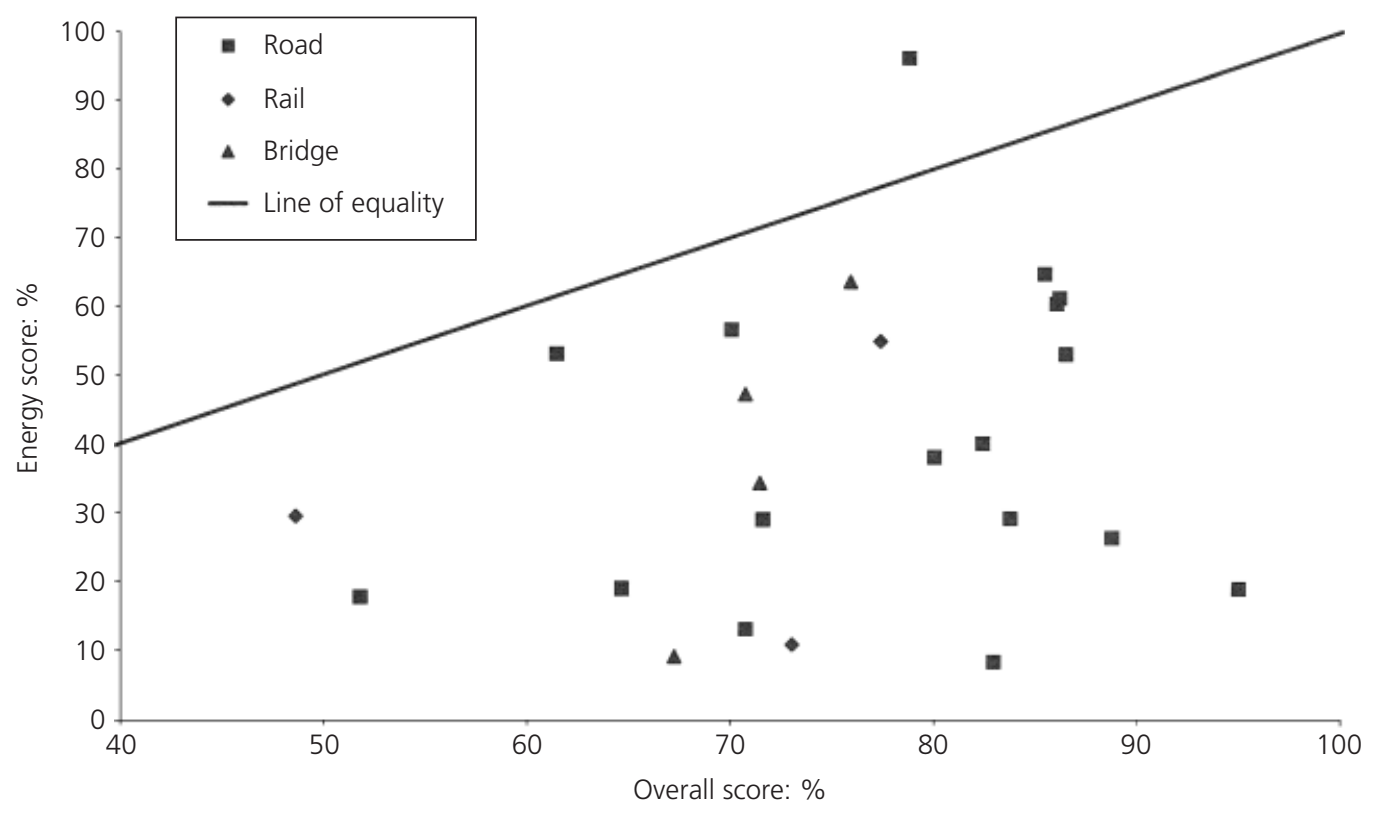

Figure 4. Scatter plot of energy scores for transport projects

there were further relationships within the road projects, that is, widening or new build, but this is not possible as highlighted earlier. The risk of excluding zero-scoring projects is highlighted in Table 2 (rail projects) where question 8.4.2 (use of high-grade reclaimed or recycled material; optional question) has a zero uptake because the three projects here all scored zero. Due to the small sample of rail projects a small variation in the number of eligible projects to answer a question can easily change the uptake from 100 to $50 \%$. Questions 8.5 .2 and 8.7.1 have 0 uptake, which is due to five projects that scored zero and one project where it was not applicable.

The road projects perform better across the range of energy questions (Table 3) but general uptake is below that of the materials section (Table 2). The small number of rail and bridge projects makes any extrapolation difficult from Tables 2 and 3. 
8.1.1 - Using a plan to minimise environmental impact*

$\begin{array}{rll}15 & 3 & 3 \\ 15 & 2 & 3 \\ 10 & 3 & 3 \\ 15 & 0 & 1 \\ 16 & 2 & 2 \\ 16 & 1 & 3 \\ 15 & 0 & 2 \\ 14 & 2 & 4 \\ 13 & 1 & 4 \\ 11 & 2 & 4 \\ 12 & 1 & 3 \\ 11 & 0 & 3 \\ 16 & 2 & 1 \\ 11 & 1 & 3 \\ 6 & 0 & 1 \\ 6 & 1 & 2 \\ 14 & 2 & 3 \\ 12 & 2 & 3 \\ 2 & 0 & 1 \\ 13 & 1 & 4 \\ 12 & 1 & 3\end{array}$

8.1.2 - Implementation of plan*

8.2.1 - Consideration of environmental benefits*

8.2.2 - Cut and fill optimisation

8.2.3 - Re-use of excavated material

8.2.4 - Soil separation and storage

8.2 .5 - Soil re-use

8.2.6 - Avoiding material waste through breakage*

8.3.1 - Sustainable use of timber (permanent)

8.3.2 - Sustainable use of timber (temporary)

8.4.1 - Re-use of existing structures

8.4.2 - Recycled materials in permanent works*

8.4.3 - Use of reclaimed material (bulk fill)

8.5.1 - Factory applied coatings

8.5.2 - Low VOC/biodegradable coatings

8.5.3 - Extension of COSHH assessment*

8.6.1 - Durability and maintenance

8.6.2 - Long-term maintenance plan*

8.7.1 - Design for disassembly

8.7.2 - Ease of separation of materials (deconstruction)

8.7.3 - Materials register for client*

Table 2. Number of projects scoring questions in the materials section

\begin{tabular}{|c|c|c|c|}
\hline Question & Road projects & Rail projects & Bridge projects \\
\hline 7.1.1 - Life-cycle energy analysis* & 1 & 1 & 0 \\
\hline 7.1.2 - Implementation of analysis* & 1 & 0 & 0 \\
\hline 7.2.1 - Operational energy consumption* & 9 & 1 & 3 \\
\hline 7.2.2 - Reducing energy consumption in use & 9 & 0 & 2 \\
\hline 7.2.3 - Energy from renewable sources & 5 & 2 & 2 \\
\hline 7.2.4 - Incorporation of renewable energy & 3 & 1 & 1 \\
\hline 7.3.1 - Energy consumption during construction* & 13 & 0 & 1 \\
\hline 7.3.2 - Reducing energy consumption in construction & 13 & 0 & 0 \\
\hline 7.3.3 - Energy management plan* & 11 & 0 & 1 \\
\hline 7.3.4 - Energy efficiency of construction plant* & 5 & 1 & 2 \\
\hline 7.3.5 - Renewable energy during construction* & 4 & 0 & 1 \\
\hline 7.3.6 - Fuel efficiency of construction plant* & 12 & 2 & 3 \\
\hline 7.3.7 - Monitoring of energy use on site* & 11 & 0 & 3 \\
\hline
\end{tabular}

\section{Analysis and discussion}

This paper has shown the split of transport projects (Figure 1) and the graphs in Figures 3 and 4 highlight the prominence of road projects in particular within the sample. To draw meaningful conclusions from the data, road projects will form the basis of the analysis and discussion. As further rail and bridge project data become available it may be necessary to revisit these Ceequal project types in a future study. 
The disparity (at the level of all transport projects) between materials and energy appears to indicate that the two sections are not linked; however, a few questions do cross over and are discussed later in this section. Energy assessment is an area of concern as the average score of $39 \%$ (Figure 2) is the lowest average of all the 12 Ceequal sections. In a period where there is a significant drive to reduce carbon and energy demands this would appear to be a poor reflection on the projects themselves or the way in which the questions are structured; it should also be borne in mind that these projects have been completed using version 3.1 of the manual and therefore could have been completed up to 5 years ago when the political and economic environment was very different and therefore will have been designed and planned more than 5 years ago.

By focusing on the 17 road projects it is possible to identify the rate of 'scoping out' of the optional questions for materials and energy. Table 4 shows that over the 17 road projects $5 \%$ of the materials questions and $3 \%$ of the energy section were 'scoped out'. While these figures appear similar, the flexibility of each question set needs to be understood. The materials section has 21 questions (of which eight cannot be scoped out, i.e. are mandatory) thereby giving a maximum of $62 \%$ of points that could be scoped out. By comparison the energy question set seems more rigid with a total of 13 questions (of which nine cannot be 'scoped out') meaning that only $30 \%$ of points could be scoped out. One of the strengths of Ceequal is the flexibility of the question set; but perhaps one of the reasons the energy section had the lowest average score and a low correlation with project scores is that the principles of energy use are more universally applied than materials use which can be more project specific.

From Tables 5 and 6 the average zero scores have been calculated as $28 \%$ for the mandatory questions and $21 \%$ for the optional questions. This may be expected as projects could be more likely to score a zero in a mandatory question than an optional question that could be scoped out with the appropriate evidence. However, it could also be argued that the averages are similar and therefore proof that the scoping out process works well. What the data do not show is whether the project team felt that it would have been desirable and justified to scope out a mandatory question, but is beyond the scope of this study. The relatively small gap between the two averages might suggest that the materials questions are not particularly easy to scope out. Of the mandatory questions the lowest and highest zero scores stand out, these being questions 8.2.6 and 8.5.3. Question 8.2.6 asks, 'Is there evidence that materials have been stored appropriately so as to avoid waste through breakage?'. The evidence requirement could be photographic or site records to this effect, but it must show a sustained effort for this question for the duration of the project. With only $7 \%$ of road projects scoring zero for this section, it is clear that project teams actively pursue this question. Question 8.5.3 has a high zero score rate of $63 \%$, but this may be due to the very specific nature of extending the control of substances hazardous to health (COSHH) assessment process to cover the wider environmental impacts of the materials whereas a number of questions in the materials section are broad and generic. This question (8.5.3) is very prescriptive, leaving no room for

\begin{tabular}{lccc}
\hline Road project; section & Maximum score before scoping & Maximum score after scoping & Percentage scoped out \\
\hline Materials & 1564 & 1486 & $5 \%$ \\
Energy & 1375 & 1340 & $3 \%$
\end{tabular}

Table 4. Road projects: materials and energy section - points

scoped out

Question

Using a plan to minimise environmental impact - 8.1.1

Implementation of plan - 8.1.2

Consideration of environmental benefits -8.2 .1$

Avoiding material waste through breakage -8.2 .6$

Recycled materials in permanent works - 8.4.2

Extension of $\mathrm{COSHH}$ assessment -8.5 .3$

Long-term maintenance plan - 8.6.2

Materials register for client -8.7 .3$
Zero score

$12 \%$

$12 \%$

$41 \%$

$7 \%$

$35 \%$

$63 \%$

$25 \%$

$25 \%$

Table 5. Road projects: mandatory materials questions with a zero

score 


\begin{tabular}{lr}
\hline Question & Zero score \\
\hline Cut and fill optimisation -8.2 .2 & $6 \%$ \\
Re-use of excavated material -8.2 .3 & $0 \%$ \\
Soil separation and storage -8.2 .4 & $0 \%$ \\
Soil re-use - 8.2.5 & $6 \%$ \\
Sustainable use of timber (permanent) - 8.3.1 & $13 \%$ \\
Sustainable use of timber (temporary) - 8.3.2 & $27 \%$ \\
Re-use of existing structures -8.4 .1 & $20 \%$ \\
Use of reclaimed material (bulk fill) - 8.4.3 & $0 \%$ \\
Factory applied coatings - 8.5.1 & $31 \%$ \\
Low VOC/biodegradable coatings - 8.5.2 & $63 \%$ \\
Durability and maintenance - 8.6.1 & $7 \%$ \\
Design for disassembly - 8.7.1 & $83 \%$ \\
Ease of separation of materials (deconstruction) - 8.7.2 & $19 \%$ \\
Table 6. Road projects: optional materials questions with a zero & \\
score & \\
\hline
\end{tabular}

interpretation; only three of the 17 road projects scored maximum points for this question. Ceequal could perhaps recognise the legal compliance of COSHH and award points for this and award further points for those who exceed these requirements; however, Ceequal is about best practice and is focused on pushing beyond legal compliance.

The energy section presents a different profile for road projects. The basic principles have poor participation levels with $94 \%$ of projects with zero scores. The first two questions in Table 7 are 7.1.1 and 7.1.2. These are the most critical in relation to the assessment of materials, as 7.1.1 asks, 'Has a life-cycle energy analysis been undertaken for the key materials and component to be used in the project?'. Question 7.1.2 follows on from this and asks what percentage of the recommendations have been incorporated into the design and completed works. Only one of the 17 road projects scored points on these two questions.
Questions 7.2.3 and 7.2.4 relate to the identification and use of renewable energy. These questions can be scoped out if the use of renewable energy is not applicable or the sourcing of such energy is not appropriate or possible. With this in mind the fact that over $50 \%$ of road projects scored zero (Table 8 ) on these questions may need further investigation, as it should be quite feasible to be able to demonstrate the feasibility of using renewable energy sources in a project; alternatively this question could be scoped out for road projects.

The link to 8.2.1 (environmental impact of component parts) could also be addressed by answering questions 7.1.1 and 7.1.2 in a robust manner. The question set could be condensed here and re-phrased to reflect the commonality of these issues. Similarly 8.7.1 could also be addressed through a LCA. These four questions could be condensed into one with the focus on the undertaking of the LCA, implementation where possible and how

\begin{tabular}{lc}
\hline Question & Zero score \\
\hline Life cycle energy analysis - 7.1.1 & $94 \%$ \\
Implementation of analysis - 7.1.2 & $94 \%$ \\
Operational energy consumption - 7.2.1 & $44 \%$ \\
Energy consumption during construction - 7.3.1 & $19 \%$ \\
Energy management plan - 7.3.3 & $31 \%$ \\
Energy efficiency of construction plant - 7.3.4 & $69 \%$ \\
Renewable energy during construction -7.3 .5 & $75 \%$ \\
Fuel efficiency of construction plant - 7.3.6 & $25 \%$ \\
Monitoring of energy use on site - 7.3.7 & $31 \%$ \\
Table 7. Road projects: mandatory energy questions with a zero & \\
score &
\end{tabular}


Reducing energy consumption in use -7.2 .2$

Energy from renewable sources -7.2 .3$

Incorporation of renewable energy - 7.2.4

Reducing energy consumption in construction - 7.3.2

Table 8. Road projects: optional energy questions with a zero score

\section{$40 \%$}

$62 \%$

$73 \%$

$19 \%$ the process has helped the design and construction process. Question 7.3.5 (mandatory) asks, 'Has energy from renewable sources been used during construction?'. This question is mandatory and seems to penalise the project where it may not be economically feasible to use such energy. Similar opportunities to shorten the question set may exist with the waste, water and other sections, but further work needs to be done to ascertain this.

Indeed a streamlined version of Ceequal is certainly plausible but it may also be possible to produce a road project-specific version of the Ceequal manual. The only other non-transport category with sufficient data to make any sort of comparison against is water; Table 9 highlights the stronger performance in the energy section of the water projects and slightly lower average score in the materials section. The term 'maintenance version of Ceequal' is being piloted at the moment and some of the lessons learned from this trial could feed into an extension of this work to develop a Ceequal manual that is less demanding on project resource but still addresses the range of environmental and social aspects of the full Ceequal manual. A further consideration of any new shortened or project-specific version of the Ceequal manual would be the weightings identified in Table 1; an alteration of the question set would itself change the weightings and further modifications would be necessary to re-balance the points embedded in the questions. As LCA becomes more of a key issue and mechanism by which to account for a range of issues including waste, water, energy and carbon, it will be necessary to place such questions together in a unique section or to place cross-references in other sections.

This work has used version $3 \cdot 1$ of the Ceequal manual. Version 4 was launched in November 2008 and some revisions have been

\begin{tabular}{lcccccc}
\hline & \multicolumn{2}{c}{ Average score } & & \multicolumn{2}{c}{ Regression } \\
\cline { 2 - 3 } \cline { 5 - 6 } & Materials & Energy & & Materials & Energy \\
& & & & & & \\
& 74 & 40 & & 0.752 & 0.030 \\
Road projects & 70 & 47 & & 0.798 & 0.152
\end{tabular}

Table 9. Road projects and water projects in comparison made to both the materials and energy sections (the inclusion of responsible sourcing as a separate question set and a life-cycle question focusing on carbon footprinting). Although these additions further refine the questions there remain areas of the materials questions that could be revised and structured more effectively to serve users of the manual. More fundamentally the development of specific Ceequal schemes would allow for a greater degree of specification-led assessment rather than purely evidence-based.

\section{Conclusions}

The aim of this research was to understand the relationships between overall project scores and section scores for materials and energy for a sample of Ceequal projects that were transport related. Scores in the materials section showed a positive relationship with the overall project score for the range of transport projects, whereas the energy section data had a poor correlation in general. The individual analysis of road, rail and bridge projects for materials and energy question sets highlighted the reliance and bias of the sample set to road projects, which then focused the remainder of the research. As the weightings for both materials and energy were above $8 \cdot 3 \%$ (the nominal weighting if there was no weighting, i.e. $1 / 12$ ), both sections only benefit from the weighting. In addition as the weighting factors are only $1 \%$ different, it stands that the weighting itself does not impact significantly on the scores when comparing materials and energy sections in this context.

The analysis of the impact of the 'scoped out' questions appears to have had little overall impact on the road projects with only $5 \%$ of energy questions and 3\% of materials questions (points basis) being 'scoped out'. The disparity between correlations identified at the project level cannot therefore be attributed to project teams deciding to deselect particular questions. Scoping out takes place early on in the assessment and is agreed between the assessor and a Ceequal verifier; the zero scores and low impact would suggest that the scoping out process is robust. Some questions were identified that had very poor performance (based on percentage of zero scores); some of these related to LCA and therefore link materials and energy assessment.

It would be possible to rationalise the question set in Ceequal through the identification of common areas such as LCA where 
Transport

Volume 164 Issue TR3
Materials and energy assessment in

Ceequal transport projects

Ghumra, Glass, Frost, Watkins and Mundy the outputs of a complete assessment over the whole life of the materials could address issues such as product selection, embodied carbon, maintenance considerations, durability and renewable energy. This study has highlighted the inter-relationship between materials and energy assessment in Ceequal, but acknowledges that there are links to other sections such as waste; it would therefore be desirable for this type of analysis to be extended to the other ten sections of Ceequal not analysed in this paper. A project-specific version of Ceequal may be possible, but without sufficient projects completed in other civil engineering sectors it is difficult to conclude what benefit this would bring. Further research is strongly advised in light of this work in order to study the question set in more detail in order to remove duplication and increase the level of specification in the assessment.

Although Ceequal and Breeam have similar holistic aims the two schemes are technically very different using different methodologies. It is accepted that building construction is fundamentally different to civil infrastructure but areas of common ground do exist, for example, responsible sourcing compliance and questions relating to LCA. A further recommendation for the development of Ceequal (and also Breeam) would be a greater similarity in the assessment approach on common issues. A more rationalised question set with this in mind would benefit clients who seek both Ceequal and Breeam awards on the same project. Ceequal has steadily evolved over the past few versions but now needs to take the next jump forward with a complete revision of the themes for each section and the cross-cutting questions that weave between them.

As more emphasis is placed on sustainable development in transportation and more specifically on materials and energy use, the findings of this research should be fed into the development of Ceequal.

\section{Acknowledgements}

The authors would like to thank Ian Nicholson from Ceequal for providing the data and offering guidance for this publication. This work is part of a collaborative Engineering Doctorate between Aggregate Industries, BRE and the CICE at the Department of Civil and Building Engineering at Loughborough University funded by EPSRC.

\section{REFERENCES}

BRE (Building Research Establishment) (2008) BREEAM Industrial Manual. BRE, Watford, UK.

BRE (2009) BES 6001: Issue 2.0: Framework Standard for the Responsible Sourcing of Construction Products. BRE, Watford, UK. See http://www.greenbooklive.com/filelibrary/ responsible_sourcing/BES_6001_Issue2_Final.pdf (accessed 27/06/2011).

BSI (2008) PAS 2050: Specification for the Assessment of the Life Cycle Greenhouse Gas Emissions of Goods and Services. BSI, Milton Keynes, UK. See http://shop.bsigroup.com/en/
Browse-by-Sector/Energy-Utilities/PAS-2050/(accessed 02/06/2010).

Ciria (Construction Industry Research and Information Association) (2007) The Civil Engineering Environmental Quality Assessment and Awards Scheme Manual, Version 3.1. CIRIA, London, UK.

Ciria (2008) The Civil Engineering Environmental Quality Assessment and Awards Scheme Manual, Version 4.0. CIRIA, London, UK.

EA (Environment Agency) (2009) Carbon Calculator for Construction Activities. EA, London, UK. See http:// www.environment-agency.gov.uk/business/sectors/37543.aspx (accessed 02/06/2010).

FFTF (Forum for the Future) (2009) Carbon Management for Major Infrastructure Projects. FFTF, London, UK. See http:// www.forumforthefuture.org/project/engineers-21st-century/ more/carbon-management-major-infrastructure-projects (accessed 27/06/2011).

Ghumra S (2009) Life-cycle assessment-based tool for civil infrastructure projects. Innovation and Research Focus 77: 8.

Ghumra S (2010) Materials Assessment in BREEAM and Ceequal. EngD Short Project, Loughborough University, Loughborough, UK.

Ghumra S, Watkins M, Phillips P et al. (2009) Developing a LCAbased tool for infrastructure projects. In Proceedings of the 25th Annual ARCOM Conference, Nottingham, UK, 7-9 September 2009 (Dainty A (ed.)). Association of Researchers in Construction Management, Loughborough, UK, pp. 10031010.

Ghumra S, Glass J, Frost MW et al. (2011) Stakeholder views LCA in road pavement construction. In Proceedings of the 3rd International Conference on Infrastructure, Hong Kong, 11-12 July. Hong Kong Polytechnic University, Hong Kong (accepted).

Greeman A (2009) CEEQUAL: green gets seen. New Civil Engineer 28 May, pp. 26-29. See http://www.nce.co.uk/ ceequal-green-gets-seen/5202646.article (acessed 27/06/2011).

HA (Highways Agency) (2009) Act on $\mathrm{CO}_{2}$ Calculator. HA, London, UK. See http://carboncalculator.direct.gov.uk/ index.html (accessed: 27/06/2011).

HM Government (2008) Strategy for Sustainable Construction. Department for Business, Enterprise and Regulatory Reform, London, UK. See http://www.berr.gov.uk/files/file46535.pdf (accessed 27/06/2011).

HM Government (2010) Low Carbon Construction Innovation and Growth Team; Emerging Findings. Department for Business, Innovation and Skills, London, UK. See http:// www.bis.gov.uk/policies/business-sectors/construction/ low-carbon-construction-igt/emerging-findings (accessed 27/06/2011).

IRF (International Road Federation) (2009) CHANGER - IRF Greenhouse Gas Calculator. See http://www.irfnet.org/ activities.php?id=32\&title $=$ CHANGER - IRF Greenhouse gas Calculator (accessed 27/06/2011). 
ISO (International Standardization Organization) (2010) ISO/CD 14067-1: Carbon Footprint of Products: Part 1 Quantification. ISO, Brussels, Belgium.

Leckie S (2010) Briefing: A new approach to decarbonising infrastructure projects. Proceedings of the Institution of Civil Engineers - Engineering Sustainability 163(1): 10.
Venables R (2005) Tools for assessing the environmental performance and sustainability of building and civil engineering projects. Proceedings of the 9th International Conference on Environmental Science and Technology, Rhodes, Greece, Vol A - Oral Presentations, Pts A and B, pp. A1596-1601.

\section{WHAT DO YOU THINK?}

To discuss this paper, please email up to 500 words to the editor at journals@ice.org.uk. Your contribution will be forwarded to the author(s) for a reply and, if considered appropriate by the editorial panel, will be published as a discussion in a future issue of the journal.

Proceedings journals rely entirely on contributions sent in by civil engineering professionals, academics and students. Papers should be $2000-5000$ words long (briefing papers should be 1000-2000 words long), with adequate illustrations and references. You can submit your paper online via www.icevirtuallibrary.com/content/journals, where you will also find detailed author guidelines. 